\title{
SOBRE EL NOMBRAMIENTO DEL PRESIDENTE Y DE LOS VOCALES DEL CONSEJO GENERAL DEL PODER JUDICIAL. UNA REFLEXIÓN DESDE EL SENTIDO COMÚN
}

\author{
JUAN-LUIS GÓMEZ COLOMER \\ Catedrático de Derecho Procesal \\ Universidad Jaume I de Castellón
}

\section{SUMARIO}

I. Introducción: La creación del Consejo General del Poder Judicial español y sus funciones principales. II. El nombramiento de los Vocales del Consejo General del Poder Judicial y de su Presidente: La evolución jurídica desde la Constitución española de 1978. III. Una ojeada a nuestros vecinos: Italia, Francia, Portugal y Alemania. IV. La crítica real a la politización del Consejo, ¿es responsable la Constitución de ello? V. Los amplios límites constitucionales no favorecen una solución única y aceptable por todos. ¿Qué sería lo mejor?

\section{INTRODUCCIÓN: LA CREACIÓN DEL CONSEJO GENERAL DEL PODER JUDICIAL ESPAÑOL Y SUS FUNCIONES PRINCIPALES}

En cualquier país democrático riguroso, la organización del Poder Judicial, del mismo modo que la del Poder Ejecutivo y la del Poder Legislativo, puede hacerse de varias maneras o siguiendo modelos diferentes. Pero, respetando la diversidad, toda construcción organizativa de su Poder Judicial únicamente puede tener un fin, excluyente y exclusivo respecto a todos los demás, a saber: Garantizar la independencia total, sin matices, de sus miembros, los jueces, cuando ejerzan la función jurisdiccional. ${ }^{1}$

Independencia judicial significa exclusiva sumisión a la ley. Sin entrar en otros detalles, pues sobre este tema se han escrito ríos de tinta en cualquier

1 Véanse Montero Aroca, J. / Gómez Colomer, J.L. / Barona Vilar, S., «Derecho Jurisdiccio-

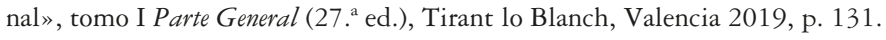


idioma, la sumisión a la ley es el precio que ha habido que pagar para liberarse de la intromisión del poder, especialmente del soberano, en la época medieval y moderna. ${ }^{2}$

Se dirá, con razón, que la independencia no es el único principio que afecta al Poder Judicial. No lo niego, pero todos los que en España objetiva (unidad, exclusividad y juez legal), y subjetivamente (responsabilidad, inamovilidad, imparcialidad), configuran constitucionalmente el Poder Judicial, deben tener siempre presente que la razón de su existencia es ayudar a que el principio de la independencia sea una realidad tangible en el país en el que ese poder actúa, por eso son principios que garantizan la independencia, a un nivel inferior respecto a ella.

Aunque probablemente con otras preocupaciones, no menores, en sus mentes, esta idea estuvo presente en quienes redactaron la Constitución española, y nadie osó discutirla o incluso apartarla de ella, pues la independencia judicial se recoge en varios preceptos (arts. 117.1, 117.2, 124.1 y 127.2, entre otros). Además, por un lado, se rodeó de principios clave para hacerla efectiva, acabados de aludir, y por otro, se creó un órgano para garantizarla, el Consejo General del Poder Judicial. ${ }^{3}$

La creación de este consejo, afirmo por ahora, implicó coherentemente que se restasen competencias al Ministerio de Justicia (y por extensión a las futuras Comunidades Autónomas), en una clara acción a favor de hacer realidad en nuestro país que los jueces no estuviesen controlados políticamente. A este fenómeno, visible en la maniobra constitucional de creación del Consejo a la que me referiré de inmediato, se le ha llamado desapoderamiento del ejecutivo. ${ }^{4}$

De los diversos ámbitos que están implicados en este tema, hoy me voy a referir sólo a uno de ellos, el aludido Consejo General del Poder Judicial, sin precedente histórico alguno en nuestro país ${ }^{5}$, con la intención de demostrar que, con el desarrollo posterior a su puesta en marcha, la independencia judicial queda

2 Simon, D., La independencia del juez (trad. Ximénez-Carrillo), Ariel, Barcelona 1985, p. 71.

3 La bibliografía española sobre la Justicia en la Constitución vigente y, en particular, sobre el Consejo General del Poder Judicial es inabarcable. En este artículo, lógicamente limitado en cuanto al espacio, no puedo por ello recoger toda la doctrina procesalista, constitucionalista y administrativista que han tratado estos temas, ciñéndome a aquélla que ha generado un debate fructífero y aportado soluciones útiles, aunque puedan ser muy discutibles, sobre el objeto principal del mismo. No obstante, para una breve aproximación inicial, es de citar Rodríguez-Aguilera, C., El Consejo General del Poder Judicial, Bosch, Barcelona 1980, esp. pp. 25 a 41. Es interesante leer el pensamiento inmediatamente anterior, en la época franquista tardía, de los autores que se ocuparon del tema, v.gr., Gutiérrez de CABIEdes, E., Observaciones al tema del autogobierno de la Magistratura, en «Estudios de Derecho Procesal», Universidad de Navarra, Pamplona 1974, pp. 109 y ss.; y Prieto-Castro y Ferrándiz, L., El autogobierno de la Magistratura, en «Temas de Derecho actual y su práctica», Universidad de Salamanca 1979, pp. 329 y ss.

$4 \mathrm{El}$ apoderamiento del poder judicial por el poder político no es tan novedoso, ni en España, ni en el resto de Europa, por eso hay que estar siempre alerta, véase Montero Aroca, J., Independencia y responsabilidad del Juez, Civitas, Madrid 1990, p. 28.

5 Un apretado resumen en Alzaga Villaamil, Ó., Comentario sistemático a la Constitución española de

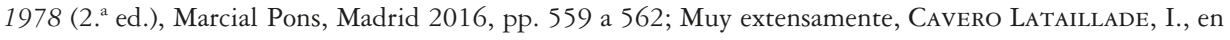


lejos de estar garantizada, lo que no deja de ser un contrasentido del sistema, pues se creó precisamente para hacerla real, para hacerla cumplir, para ser el fundamento principal, si no único, del sistema judicial.

No todo el Consejo merece una crítica conceptual tan negativa. Su propia existencia era necesaria. Algunos aspectos sin embargo no tienen una valoración tan favorable, más bien al contrario. Me voy a referir en este artículo particularmente al sistema de nombramiento de los vocales que componen el Consejo General del Poder Judicial, porque creo que es aquí en donde está el problema más importante que se plantea hoy con relación a esa independencia.

Antes diré que las previsiones relativas al Consejo General del Poder Judicial se recogen en la Constitución española, en su artículo 122.3. El número 1 de ese artículo 122 marca un contenido claro para la futura ley, dos veces orgánica (por la reserva legal y por ser de organización) del poder judicial (aprobada en 1985). ${ }^{6}$ Y el número 2 de ese mismo precepto, que crea realmente la institución, se preocupa de su contenido mínimo.

No está claro hoy a la vista de su evolución práctica si realmente es un órgano de autogobierno, y tampoco lo es que sea, en calidad rebajada, un órgano de gobierno, más bien hoy parece un simple, aunque de altísimo nivel, órgano de gestión. Pero, como apunté, la creación del Consejo General del Poder Judicial ha sido una, en principio, «magnífica idea» que el tiempo ha ido poniendo en su lugar, es decir, ha ido rebajando a la categoría de sólo «idea».

El desarrollo se confía por la Constitución a una Ley Orgánica. Pero el artículo 122.3 fija claramente los límites que afectan a su nombramiento y formación. Son los siguientes: a) Veinte miembros (si el presidente del Tribunal Supremo no forma parte de ellos, son en realidad veintiuno el total de componentes). b) Elegidos: Doce, entre Jueces y Magistrados, Ocho entre abogados y juristas de reconocida competencia con más de 15 años de ejercicio profesional, elegidos por mayoría de 3/5. De ellos, cuatro a propuesta del Congreso y cuatro a propuesta del Senado.

Obsérvese por tanto que esos veinte o veintinún miembros se han de preocupar de lo esencial: Gobernar al Poder Judicial. En realidad, implica formalmente el autogobierno (más bien la gestión) judicial por un órgano constitucional, siempre en lo relativo a las funciones no jurisdiccionales de los jueces y magistrados que estén reconocidos por la Ley Orgánica del Poder Judicial. ${ }^{7}$

Y obsérvese también, curiosamente, que no se declara en la Constitución como fin principal del Consejo General del Poder Judicial garantizar la

Alzaga Villaamil, Ó. (Dir.), Comentarios a la Constitución española de 1978 (2. ${ }^{a}$ ed.), Cortes Generales y EDERSA, Madrid 1998, tomo IX (artículos 113 a 127), pp. 443 a 519.

6 Sobre su tramitación parlamentaria, v. con amplitud Cavero Lataillade, I., en Alzaga VillaAMIL, Ó. (Dir.), Comentarios a la Constitución española de 1978, cit., pp. 459 y ss.

7 Cavero lataillade, I., en Alzaga Villaamil, Ó., Comentario sistemático a la Constitución española de 1978 , cit., p. 473. 
independencia de los jueces que forman parte del Poder Judicial. Pero es verdad que sí se afirma su función tutelar respecto a la independencia de los jueces en el art. 14.1 LOPJ, que regula la independencia, además de en sus arts. 1, 12 y $13 .{ }^{8}$

\section{EL NOMBRAMIENTO DE LOS VOCALES DEL CONSEJO GENERAL DEL PODER JUDICIAL ESPAÑOL Y DE SU PRESIDENTE: LA EVOLUCIÓN JURÍDICA DESDE LA CONSTITUCIÓN ESPAÑOLA DE 1978}

Tras la Constitución, una de las primeras tareas a realizar era aprobar la ley orgánica de desarrollo de las previsiones sobre el estatuto de los jueces y magistrados y del Consejo General del Poder Judicial. Un tema éste último aparentemente sencillo, que el tiempo ha demostrado ser mucho más complicado de lo que parecía.

En efecto, para conocer bien lo que ha sucedido es necesario que tengamos en cuenta la evolución normativa de esta institución. ${ }^{9}$ Es importante saber también con qué gobierno se aprueba cada ley o reforma, pues sólo así se constata que el Consejo ha sido uno de los mayores objetos del deseo de todos los gobiernos democráticos que España ha tenido desde 1978, salvo del primero probablemente (v. a continuación).

$\left.1 .^{\circ}\right)$ Con relación al Consejo General del Poder Judicial, la idea inicial fue desarrollar el art. 122.3 CE mediante una ley orgánica propia, de creación del propio Consejo. Esto sucede muy pronto, en 1980, dos años después de aprobada la CE, con la aprobación de la Ley Orgánica 1/1980, de 10 de enero, del Consejo General del Poder Judicial, ${ }^{10}$ pero por razones ajenas al propio CGPJ: ${ }^{11}$

Centrándonos en la elección de sus miembros, la Ley de 1980 reiteró lo dispuesto por la Constitución, salvo en quién elegía a los jueces, algo que silenció la

8 La redacción constitucional del Poder Judicial y en concreto del Consejo General del Poder Judicial, tras un debate infinitamente extenso de la ponencia, «no dejó a nadie buen sabor de boca sobre la fórmula finalmente consensuada». Así lo atestigua Alzaga Villaamil, Ó., El proceso constituyente español visto por uno de sus protagonistas: Entrevista a Óscar Alzaga Villaamil, Historia Constitucional 2018, n. ${ }^{\circ} 19$, p. 6.

9 Me limito al período postconstitucional. Para antes de 1978 en nuestro país, v. BALlester CARDell, M., El Consejo General del Poder Judicial. Su función constitucional y legal, CGPJ, Madrid 2007, pp. 33 y ss.; y Cavero lataillade, I., en Alzaga Villaamil, Ó. (Dir.), Comentarios a la Constitución española de 1978, cit., pp. 444 y ss. De sumo interés Lasso GaITE, J.F., Crónica de la Codificación Española, tomo 1 - Organización Judicial, Ministerio de Justicia, Madrid 1970, passim. González.

10 Gobierno de Unión de Centro Democrático (UCD), presidiendo el Excmo. Sr. D. Adolfo Suárez

11 La verdadera razón por la que el CGPJ tuvo una ley propia tan tempranamente fue para que pudiera elegir a los 2 magistrados del Tribunal Constitucional (art. 159.1 CE), que se iba a poner en marcha inmediatamente como consecuencia de la LO 2/1979, de 3 de octubre, v. Cavero Lataillade, I., en Alzaga Villaamil, Ó. (Dir.), Comentarios a la Constitución española de 1978, cit., p. 481. Véase también MonTERO Aroca, J., Independencia y responsabilidad del Juez, cit., pp. 126 y ss. 
norma fundamental, quedando compuesto de la siguiente forma (arts. 7, 8 y 12): 1. Veinte miembros (si el presidente del Tribunal Supremo no forma parte de ellos, veintiuno). 2. Elegidos: Doce, entre Jueces y Magistrados pertenecientes a todas las categorías judiciales, en los términos establecidos en la presente Ley, con la siguiente proporción: Tres Magistrados del Tribunal Supremo, seis Magistrados y tres Jueces. Ocho entre abogados y juristas de reconocida competencia con más de quince años de ejercicio profesional, elegidos por mayoría de tres quintos: Cuatro a propuesta del Congreso, Cuatro a propuesta del Senado.

De manera que la elección de los jueces y magistrados, que es el punto clave, se producía entre ellos mismos. Parece lo correcto pero, como vamos a comprobar, desde el principio la elección de los vocales jueces y magistrados ha sido polémica. Respeto a los 8 vocales restantes (los no jueces), no la ha habido generalmente, aunque a veces se han elegido a algunos personajes cuya «reconocida competencia» era más que discutible, por no fijarnos en la clara filiación política de otros. ${ }^{12}$

En la práctica, el Gobierno negociaba con la oposición los nombramientos, de manera que los propuestos obtuvieran un visto bueno parlamentario por consenso sin problema alguno. ${ }^{13}$

Esta Ley Orgánica fue derogada por la Ley Orgánica del Poder Judicial, que pasamos a considerar.

$2^{\circ}{ }^{\circ}$ En efecto, la Ley Orgánica 6/1985, de 1 de julio, del Poder Judicial, ${ }^{14}$ consideró más apropiado, y no le faltaba razón jurídica, regular el Consejo General del Poder Judicial en su seno, puesto que en definitiva el órgano gubernativo de los jueces debía estar en la regulación orgánica de los mismos (arts. 111 a 113).

El cambio de la LOPJ fue radical respecto al sistema de elección de los jueces y magistrados, pues desde 1985, sin modificar la Constitución: ${ }^{15} 1$. Los jueces y magistrados en número de 12 pasaron a ser elegidos por las Cámaras y no por ellos mismos. Cada una elegía 6 miembros (vocales) por mayoría de tres quintos de sus miembros, entre Jueces y Magistrados de todas las categorías judiciales que se hallaran en servicio activo. 2. Las Cámaras nombraban también en número de 8, 4 cada una, a los demás Vocales entre abogados y juristas de reconocida competencia con más de quince años en el ejercicio de su profesión, igualmente por mayoría de tres quintos.

Se entendió que este cambio tan radical violaba el art. 122.3 de la Constitución, porque las facultades de propuesta o nombramiento del Parlamento son

12 Algunos casos los cita Lucas Murillo de la Cueva, P., La independencia y el Gobierno de los Jueces. Un debate constitucional, Reus, Madrid 2018, pp. 145 y ss. Véase también NiEto García, A., El malestar de los jueces y el modelo judicial, Trotta, Madrid 2010, pp. 41 y ss., en donde analiza, entre otras cuestiones, la primera huelga de los jueces habida en España el 18 de febrero de 2009.

13 En la primera ocasión, los jueces y magistrados fueron elegidos por votación efectuada por los miembros de la carrera judicial, eligiéndose el I Consejo (1980-1985).

14 Gobierno del Partido Socialista Obrero Español (PSOE), presidiendo el Excmo. Sr. D. Felipe González Márquez.

15 Montero Aroca, J., Independencia y responsabilidad del Juez, cit., pp. 131 y ss. 
excepcionales y han de interpretarse restrictivamente, de tal manera que, en el presente caso, la ampliación de la facultad de propuesta de cuatro Vocales por el Congreso y de otros tantos por el Senado para integrar el Consejo General del Poder Judicial, ${ }^{16}$ pasando de nombrar sólo a 8 a nombrarlos a todos, los 20, supondría convertir al legislador ordinario en poder constituyente, vulnerándose el art. 66.2 de la Constitución, pero el TC en su S 108/1986, de 26 de julio, afirmó, con argumentos discutibles, ${ }^{17}$ su constitucionalidad, aunque con advertencias al legislador de sus problemas. ${ }^{18}$

De este modo, con la LOPJ se produjo el cambio de rumbo y se empezaron a truncar las ideas constitucionales, porque con el nuevo sistema de nombramientos, pasando a ser designados todos por el Parlamento, empezó la politización del CGPJ. ${ }^{19}$

También empezó el desapoderamiento, aludido al principio y sobre el que volveremos más adelante (ap. IV).

$\left.3 .^{\circ}\right)$ Estas normas estuvieron en vigor 16 años ${ }^{20}$, hasta la modificación operada por la Ley Orgánica 2/2001, de 28 de junio, sobre composición del Consejo General del Poder Judicial, por la que se modifica la Ley Orgánica 6/1985, de 1 de julio, del Poder Judicial. ${ }^{21}$

La reforma de los arts. 111 a 113 en 2001 respetó los límites generales de la elección fijada por la LOPJ en 1985, pero complicó mucho las cosas en este tema, porque estableció un complejo procedimiento de elección de los Jueces y Magistrados en el que se implicaba directamente a las asociaciones judiciales. Se

16 La llamada «Enmienda Bandrés». V. Comentarios sobre ella en LuCAs Murillo de LA Cueva, P., La independencia y el Gobierno de los Jueces. Un debate constitucional, cit., pp. 29 y 30; y en Gerpe LANDíN, M., La composición del Consejo General del Poder Judicial, Revista del Centro de Estudios Constitucionales 1991, n. ${ }^{\circ}$ 9, pp. 155 y 156. Andrés Ibáñez, P., CGPJ, versión 1985: Un desastre anunciado, en Pedraz Penalva, E., «En torno a la designación de los Vocales del Consejo General del Poder Judicial a la luz del Estado de Derecho», Universidad de Valladolid, Valladolid 1996, pp. 207 y ss.

17 «... pero ni tal autonomía y facultad de autogobierno se reconocen en la Constitución ni se derivan lógicamente de la existencia, composición y funciones del Consejo.», añadiendo que «Lo único que resulta de esa regulación es que se ha querido crear un órgano autónomo que desempeñe determinadas funciones, cuya asunción por el Gobierno podría enturbiar la imagen de la independencia judicial, pero sin que de ello se derive que ese órgano sea expresión del autogobierno de los jueces» (FD 8). Analiza esta sentencia y las consecuencias para la independencia judicial del nuevo sistema de nombramientos del CGPJ, Terol BECERRA, M.J., El Consejo General del Poder Judicial, CEC, Madrid 1990, pp. 80 a 87.

18 FD 12 y 13 de la sentencia citada. Previamente, el Pleno del CGPJ intentó reconducir mediante la impugnación ante el TC por conflicto competencial la pérdida de competencias y el cambio del sistema de nombramiento de sus Vocales que el Proyecto aprobado de nueva LOPJ de 1985 implicaba, pero el TC en su S 45/1986, de 17 de abril, desestimó todas las cuestiones, validando la competencia de las Cortes para aprobar la ley en los términos que se produjo.

19 Así se eligieron los Consejos II, III y IV (1985-1990, 1990-1996 y 1996-2001).

20 Gobierno del Partido Popular (PP), presidiendo el Excmo. Sr. D. José-María Aznar López.

21 Consecuencia del PACTO DE ESTADO PARA LA REFORMA DE LA JUSTICIA, de 28 de mayo de 2001, que en su punto 21, dedicado al Consejo General del Poder Judicial, acordó un nuevo sistema de elección de los miembros del Consejo General del Poder Judicial. El texto completo se puede consultar en http://www.juecesdemocracia.es/pdf/pactoRefJust.pdf. 
interpretó como si estuviéramos ante una contienda electoral entre partidos. ${ }^{22}$ Se fijó además la necesidad de un número concreto de avales previos, conforme a un registro oficial, para poder ser candidato. Pero la elección interna correspondía a lo dispuesto en los estatutos de cada asociación. ${ }^{23}$

Si con la LOPJ se había empezado a hablar de politización del CGPJ, ahora con esta reforma empeoran mucho las cosas, porque se empieza a hablar también de sectarismo del órgano de autogobierno del Poder Judicial, en el que adquieren un papel relevante las asociaciones judiciales. ${ }^{24}$

$4^{\circ} .^{\circ} 12$ años después se volvió a modificar el sistema de nombramiento por la Ley Orgánica 4/2013, de 28 de junio, de reforma del Consejo General del Poder Judicial, por la que se modifica la Ley Orgánica 6/1985, de 1 de julio, del Poder Judicial, ${ }^{25}$ ley que deroga los artículos en los que tradicionalmente se regulaba el CGPJ (111 y ss.), que pasa ahora a estar ubicado en un nuevo Libro VIII, denominado «Del Consejo General del Poder Judicial», que recoge los nuevos artículos 558 y ss. LOPJ. ${ }^{26}$

La reforma de 2013 mantuvo los límites de la LOPJ de 1985 igualmente, aunque derogó el sistema de 2001, pero no para simplificarlo, sino para establecer un procedimiento de elección distinto, no sencillo tampoco: ${ }^{27}$ Se permitió la presentación de candidatos, aportando un curriculum vitae, una memoria exponiendo su plan de actuación y 25 avales, decidiendo una junta electoral especial, en forma no vinculante ni respecto a las candidaturas ni a sus avales. Los 12 puestos se reparten entre 3 magistrados del TS, 3 magistrados con más de 5 años de antigüedad y 6 jueces y magistrados sin requisitos de antigüedad. Las asociaciones judiciales, sin embargo, no perdieron ni un solo gramo de peso en su enorme poder sobre este tema. ${ }^{28}$

Creó además la figura del Vicepresidente del Tribunal Supremo (hasta entonces existía la figura del Vicepresidente del CGPJ), nombrado por el Pleno del CGPJ, a propuesta de su presidente, entre magistrados en activo del Tribunal Supremo, que no cuenta como miembro del CGPJ y que tiene sus funciones principales en el seno del TS. $^{29}$

22 Vide Lucas Murillo de la Cueva, P., La independencia y el Gobierno de los Jueces. Un debate constitucional, cit., pp. 41 y 42.

23 Con este sistema se eligieron el V y el VI Consejo (2001-2008, 2008-2014).

24 Véase la durísima nota de JUECES PARA LA DEMOCRACIA, de 5 de junio de 2017, en: http:// diariolaley.laley.es/Content/Documento.aspx? params=H4sIAAAAAAAEAMtMSbH1czUw MDA0NjI2NjNXK0stKs7Mz7M1MjA0NzAzMAUJZKZVuuQnh1QWpNqmJeYUp6ol56QmFrkklqQ6J-ak5qUkFtmGFJWmAgDOLGDPTAAAAA = = WKE.

25 Gobierno del Partido Socialista Obrero Español (PSOE), presidiendo el Excmo. Sr. D. José-Luis Rodríguez Zapatero.

26 Lucas Murillo de la Cueva, P., La independencia y el Gobierno de los Jueces. Un debate constitucional, cit., pp. 45 y 46.

27 Ha sido comentada muy brevemente por Llerena, P., La nueva Ley del Consejo General del Poder Judicial, Diario La Ley, n. ${ }^{\circ}$ 8126, 2013.

28 Objeto de inconstitucionalidad esta reforma, pero no en el tema del procedimiento de nombramiento de los vocales del CGPJ, el TC en su S 191/2016, de 15 de noviembre, la desestimó.

29 Con esta reforma se eligió el VII Consejo (2014-bis dato). 
5..$^{\circ}$ Finalmente, sólo 5 años después de la reforma anterior, se vuelve a modificar el CGPJ por la Ley Orgánica 4/2018, de 28 de diciembre, de reforma de la Ley Orgánica 6/1985, de 1 de julio, del Poder Judicial. ${ }^{30}$

La reforma de 2018, a pesar de las muchas críticas habidas, no ha afectado al procedimiento de elección de los jueces y magistrados establecido en 2013. Será, porque en el momento de escribir estas líneas no ha entrado en vigor aún, la que regule la elección para el VIII Consejo, con la importante modificación de suprimir la Comisión Permanente, una especie de mini Consejo reducido, pero con enorme poder, y de obligar a una composición paritaria entre hombres y mujeres del mismo (art. 567 y DT-3. ${ }^{a}$ ).

Por tanto, nuestro CGPJ está regulado en la Constitución y en la LOPJ, que ha sido modificada 3 veces en este punto, teniendo en cuenta que la LOPJ derogó la primera LO por la que se reguló el CGPJ.

Las consecuencias primarias, evidentes y sin paliativos de esta evolución son: $1^{\circ}{ }^{\circ}$ Que no se ha encontrado todavía la regulación ideal del Consejo General del Poder Judicial Español, y, en particular, tampoco se ha acertado con las normas que afectan a los nombramientos de sus 20 Vocales y de su Presidente; y $\left.2 .^{\circ}\right)$ Con cada reforma se ha intentado controlar políticamente más y mejor al Consejo. ${ }^{31}$

\section{UNA OJEADA A NUESTROS VECINOS: ITALIA, FRANCIA, PORTUGAL Y ALEMANIA}

No todos los países tienen un equivalente a nuestro Consejo General del Poder Judicial. No puedo analizar todos los importantes aquí, aunque sí diré que, en los países anglosajones, que carecen de esta institución, sería hoy por hoy impensable su introducción. ${ }^{32}$ De entre los que sí lo tienen me fijaré en estos tres:

30 Gobernando el Partido Popular (PP), siendo presidente el Excmo. Sr. D. Mariano Rajoy Brey.

31 Por eso el razonamiento de la S TC 108/1986, de 26 de julio, cit., FD 10, parece hoy una bendita ingenuidad: «Décimo._. . . la posición de los integrantes de un órgano no tiene por qué depender de manera ineludible de quienes sean los encargados de su designación sino que deriva de la situación que les otorgue el ordenamiento jurídico. En el caso del Consejo, todos sus vocales, incluidos los que forzosamente han de ser propuestos por las Cámaras y los que lo sean por cualquier otro mecanismo, no están vinculados al órgano proponente, como lo demuestra la prohibición del mandato imperativo (art. 119.2 de la L.O.P.J.) y la fijación de un plazo determinado de mandato (cinco años), que no coincide con el de las Cámaras y durante los cuales no pueden ser removidos más que en los casos taxativamente determinados en la Ley Orgánica (art. 119.2 citada).»

32 Porque nadie discute que en Inglaterra y en los Estados Unidos el nombramiento de los jueces sea político y que no exista carrera judicial. Véase, por ejemplo, el art. 2, sec. 2: El Presidente de Estados Unidos nombra a los magistrados del Tribunal Supremo, con plaza de por vida, sin obligación de jubilarse, aunque bajo amenaza de impeachment en caso de conducta deshonesta. Vide EsParza Leibar, I., en Gómez Colomer, J.L. (Coord.), Introducción al Proceso Penal Federal de los Estados Unidos de Norteamérica, Tirant lo Blanch, Valencia 2013, pp. 150 a 157. 
Italia, Francia y Portugal. En general, el modelo seguido es el italiano. Un caso particular es Alemania. ${ }^{33}$

\section{Francia}

En Europa, el primer consejo judicial estable ${ }^{34}$ nació en Francia (art. 83 de la Constitución de 1946, Conseil Superieur de la Magistrature). Estaba compuesto por 14 miembros, presidiendo el Presidente de la República (el Ministro de Justicia era el vicepresidente), quien tenía voto decisorio y nombraba a dos de sus miembros. Se creó, entre otras funciones, para garantizar la independencia de los jueces (art. 84, II), afirmada en ese mismo precepto.

La Constitución vigente de 1958, últimamente modificada en 2015, proclama igualmente la independencia judicial en su art. 64, I, regulando en el art. 65 el Consejo Superior de la Magistratura, que sigue presidido por el Presidente de la República, siendo el Ministro de Justicia su vicepresidente nato. La novedad es que prevé también agrupar en su seno a los fiscales, pues el Consejo Superior de la Magistratura está compuesto de dos salas, una para los magistrados y otra para los fiscales.

La composición de la sala de los magistrados es hoy de doce miembros: Además del Presidente de la República y el Ministro de Justicia, cinco magistrados y un fiscal, un consejero de Estado, designado por el Consejo de Estado, y tres personalidades que no pertenezcan ni al Parlamento ni a la carrera judicial, designados respectivamente por el Presidente de la República, el Presidente de la Asamblea Nacional y el Presidente del Senado.

Sus funciones son: Formular propuestas para los nombramientos de los magistrados del Tribunal de Casación, los de primer presidente de tribunal de apelación y los de presidente de tribunal de gran instancia. Los demás magistrados serán nombrados con su dictamen favorable. También será competente en materia disciplinaria, pero entonces preside el primer presidente del Tribunal de Casación.

33 Véanse, entre otros, Cavero lataillade, I., en Alzaga Villaamil, Ó. (Dir.), Comentarios a la Constitución española de 1978, cit., pp. 453 y ss.; Pedraz Penalva, E. (Coord.), El gobierno de la justicia: El Consejo General del Poder Judicial, cit., pp. 49 y ss.; y Ron Latas, R.P. / Lousada Arochena, J.F., Los Consejos de la magistratura y otros modelos de gobierno judicial, Anuario da Facultade de Dereito da Universidade da Coruña 2017, vol. 21, pp. 304 y ss.

34 No es razonable pensar en imitaciones o precedentes anteriores a la II Guerra Mundial, porque el concepto de Poder Judicial cambió radicalmente después de ella, empezando a calar las nuevas ideas ya en la propia Alemania. No obstante, para la situación anterior a esa época desde la Revolución Francesa, consúltense Wieacker, F., Privatrechtsgeschichte der Neuzeit, Vandenhoeck \& Ruprecht, Göttingen 1996, pp. 249 y ss.; y SсHмIDT, E., Einführung in die Geschichte der Deutschen Strafrechtspflege, Vandenhoeck \& Ruprecht, Göttingen 1995, pp. 275 y ss. Vide complementariamente BArona Vilar, S., Proceso penal desde la Historia. Desde su origen hasta la sociedad global del miedo, Tirant lo Blanch, Valencia 2017, pp. 346 a 352. 
De las competencias para nombrar magistrados y jueces, resalta ante todo la de decidir los nombramientos de los puestos más elevados de la Judicatura francesa.

Su desarrollo se ha efectuado por la Ley Orgánica 94-100 de 5 de febrero de 1994, sobre el Consejo Superior de la Magistratura. ${ }^{35}$ Su art. 1 determina cómo se eligen los cinco magistrados que forman parte del Consejo: un magistrado del Tribunal de Casación elegido por la asamblea de magistrados del mismo; un primer presidente de tribunal de apelación elegido por la asamblea de primeros presidentes de tribunales de apelación; un presidente de tribunal de gran instancia elegido por la asamblea de presidentes de tribunales de gran instancia, de primera instancia o de tribunal superior de apelación; dos magistrados de los demás juzgados y tribunales.

Obsérvese que la representación de los jueces más numerosos de Francia se limita a dos puestos en el Consejo.

Es obvio que el peligro de politización del consejo de la magistratura francés es inevitable con esta composición y con este procedimiento para los nombramientos. Ni hay autogobierno, ni queda garantizada por ello sobre el papel la independencia del juez francés. No debe sorprendernos, pues en Francia el máximo garante de la independencia judicial es el ¡Presidente de la República, acompañado de su Ministro de Justicia! (art. 64, I CF). Pero deducir de ello que en Francia la justicia está politizada es otro nivel de discusión, en el que aquí no podemos entrar. Como casi siempre, depende del uso moral del poder y de las cualidades éticas de sus miembros.

\section{Italia}

El segundo consejo judicial estable nacido en Europa ha sido el italiano. La Constitución italiana de 1947 (obsérvese, nada más concluir la tragedia de la II Guerra Mundial), reconoce, en efecto, el Consiglio Superiore della Magistratura en su art. 104.

La independencia de la magistratura italiana se recoge en el mismo art. 104, I CI, y su sometimiento sólo a la ley en el art. 101 CI. Recodemos que la magistratura en Italia se divide, con base en el art. 107, III CI, en decisora (nuestra Judicatura) y requirente (nuestra Fiscalía).

El Consiglio Superiore está formado por veintisiete miembros. A su cabeza está el Presidente de la República, y forman parte de él además (por cuatro años sin posibilidad de reelección quienes no sean institucionales): dos miembros natos: El Primer Presidente del Tribunal Supremo y el Fiscal General del Tribunal

35 Loi organique n 94-100 du 5 février 1994 sur le Conseil supérieur de la magistrature, accesible en: https://www.legifrance.gouv.fr/affichTexte.do?cidTexte=JORFTEXT000000364282. 
Supremo. Los demás componentes serán elegidos: dieciséis, por la totalidad de los magistrados ordinarios entre los pertenecientes a las diversas categorías, y ocho, por el Parlamento en sesión conjunta entre catedráticos titulares de universidad en materias jurídicas y abogados con quince años de ejercicio.

El número de veinticuatro elegibles no lo fija la Constitución, sino el art. 1 de la Ley de 24 de marzo de 1958, número 195, de Normas sobre la constitución y funcionamiento del Consejo Superior de la Magistratura, últimamente reformada en $2002 .{ }^{36}$

Sus funciones son, conforme al art. $105 \mathrm{CI}$, las derivadas del estatuto especial de que gozan los jueces: Las admisiones, destinos y traslados, ascensos y medidas disciplinarias en relación con los magistrados, además de las puntualmente previstas en los arts. 106 y 107 CI (designación de vocales del Tribunal Supremo por méritos especiales de catedráticos titulares de Universidad en disciplinas jurídicas y abogados que tengan quince años de ejercicio; y resolución para destituir, suspender o destinar a jueces otros cargos o funciones).

Sorprendentemente para nosotros, el Ministro de Justicia italiano tiene también la facultad de incoar expedientes disciplinarios a jueces (art. 107, II CI). Pero es más decisivo el art. $110 \mathrm{CI}$, pues «sin perjuicio de las competencias del Consejo Superior de la Magistratura, corresponden al Ministerio de Justicia la organización y el funcionamiento de los servicios relativos a la justicia.»

Respecto al modelo francés visto, y al portugués y alemán, por ver inmediatamente, destacamos un mayor compromiso en Italia a favor de un órgano institucional menos dependiente del ejecutivo y más autónomo. Que, de veintisiete miembros, veinticuatro sean elegidos (dieciséis de ellos, es decir, muchos más de la mitad, por los propios jueces de cualquier categoría), dice mucho a favor de ser un órgano realmente autónomo. Además, y ello influye mucho más de lo que se piensa, las comisiones no se constituyen si no hay un mínimo de jueces y juristas de reconocido prestigio, adoptándose sus decisiones por mayoría (art. 6 Ley 1958).

A pesar de ello, ha habido muchas tensiones de carácter político en los últimos años, debidas al enorme peso de las asociaciones judiciales, plenamente identificables con partidos políticos, y a la lucha contra la corrupción abanderada por determinados fiscales y jueces (Mani Pulite), convertidos en héroes y por tanto molestos al poder, que han marcado al Consejo. ${ }^{37}$

Se reconoce sin dudar por nuestra doctrina constitucionalista y procesalista que Italia, que fue en lo general uno de nuestros modelos constitucionales, influyó particularmente también en forma decisiva en lo relativo al Consejo. Eso no

36 LEGGE 24 marzo 1958, n. 195 (in Gazz. Uff., 27 marzo, n. 75). - Norme sulla Costituzione e sul funzionamento del Consiglio superiore della Magistratura, accesible en https://www.csm.it/documents/21768/112811/ Legge $+24+$ marzo + 1958 +n.195/a3743c54-39fb-4768-9cb6-10bcf1b8bb4b.

37 Ballester Cardell, M., El Consejo General del Poder Judicial. Su función constitucional y legal, CGPJ, Madrid 2007, pp. 82 a 84. 
quiere decir, como hemos visto, que se tratara sólo de copiar, muy al contrario, nuestro Consejo es muy distinto, en lo bueno, y en lo malo. ${ }^{38}$ En España sería impensable un Consejo presidido por el Rey y mucho menos por el Presidente del Gobierno.

\section{Portugal}

Los jueces portugueses son también independientes, sometidos sólo a la ley (art. 203 de la Constitución de 1976). Se organizan estatutariamente formando un cuerpo único (art. 215.1 CP). El presidente de su órgano más alto, el Tribunal Supremo de Justicia, es elegido por los Magistrados de éste (art. 210 CP).

El art. 218 CP prevé el Consejo Superior de la Magistratura (Conselho Superior da Magistratura), presidido por el Presidente del Tribunal Supremo de Justicia y compuesto por dieciséis vocales, elegidos: Dos designados por el Presidente de la República; siete elegidos por la Asamblea de la República; siete Jueces elegidos por sus pares, conforme al principio de la representación proporcional.

Teniendo en cuenta la situación revolucionaria que llevó a la democracia a Portugal en 1974, la Constitución no puede estar alejada de esos ideales, de ahí que estemos también ante un órgano político atendida esa composición, ya que más de la mitad son designados por el Parlamento y por el Presidente de la República. En la realidad, esto significa control del Consejo por los partidos políticos mayoritarios. ${ }^{39}$

Se recogen algunas de las competencias de dicho Consejo en el art. $217 \mathrm{CP}$ : El nombramiento, el destino, el traslado y la promoción de los Jueces de los Tribunales judiciales, así como el ejercicio de la potestad disciplinaria, competen al Consejo Superior de la Magistratura, en los términos establecidos por la ley. Por su parte, podemos deducir del art. 218.3, que prevé la participación de asesores externos en dicho Consejo, que otra de ellas es la relativa a la apreciación del mérito profesional.

Su desarrollo se encuentra principalmente en el Estatuto de los Magistrados Judiciales (arts. 136 y ss. de la Ley 21/85, de 30 de julio), reformada en 2011. ${ }^{40}$

38 Zanon, N., Profili costituzionali dell'Ordinamento Giudiziario: Autonomia e independenza della Magistratura, en Biavati, P. / Guarneri, C. / Orlandi, R., Zanon, N., «La giustizia civile e penale in Italia», Il Mulino, Bologna 2008, pp. 85 y ss. También, Alvazzi del Frate, P., Justicia y Política en Italia: la independencia del Poder Judicial y el Consejo Superior del Poder Judicial (trad. G. Vestri), Lex Social, Revista de los Derechos Sociales 2011, n. ${ }^{\circ} 1$, pp. 197 y ss.

39 Véanse De Figueiredo Dias, J., Do «Governo da Justiça ao «Governo dos Juizes no Portugal de hoje, en Pedraz Penalva, E., «En torno a la designación de los Vocales del Consejo General del Poder Judicial a la luz del Estado de Derecho», cit., pp. 83 y ss.; y Ballester CARdell, M., El Consejo General del Poder Judicial. Su función constitucional y legal, cit., p. 86.

40 Lei n. ${ }^{\circ}$ 21/85 de 30 de Julbo, Estatuto dos Magistrados Judiciais, accesible en: https://www.csm.org.pt/ wp-content/uploads/2017/02/Estatuto-dos-Magistrados-Judiciais-21-85-alteracao-9-2011-de-12-04.pdf. 


\section{Alemania}

Los jueces en Alemania son federales si forman parte de los tribunales federales de la jurisdicción ordinaria, en otro caso son estatales (de los Länder). ${ }^{41}$ Los jueces de los tribunales estatales son los más numerosos, regulados en la Gerichtsverfassungsgesetz (GVG), y atienden a la Justicia ordinaria en cualquiera de sus órdenes, ${ }^{42}$ aunque en los Länder también existen, con base en el art. 100 de la Ley Fundamental de Bonn o Grundgesetz (GG), tribunales constitucionales (excepto en Schleswig-Holstein). ${ }^{43}$

Por supuesto, todos ellos tienen garantizada constitucionalmente su independencia (art. 97 GG, § 1 de la GVG $^{44}$ y $§ 25$ de la Ley Judicial Alemana). ${ }^{45}$

Aunque pueda parecer que la Justicia alemana debería tratar la selección de sus jueces en forma exquisita, la realidad lo desmiente y, además, su procedimiento de selección parece a primera vista inaceptable para la democracia española: Los jueces son designados por la llamada Comisión de Elección Judicial (Richterwablauschuss), formada por 36 miembros: 16 ministros de justicia de los Länder y 16 expertos nombrados por el Bundestag, sean o no diputados, aunque sí deben ser juristas (art. 95.2 GG). La mayoría simple decide en secreto. Son nombrados por el Presidente de la República o por el Ministro de Justicia. ${ }^{46} \mathrm{Al}$ ser un órgano político, se entiende que la politización está asegurada, rodeada de un hálito nada beneficioso de opacidad.

41 Son cinco (art. 95.1 GG), excluyendo ahora al Tribunal Constitucional: El Tribunal Supremo Federal para Asuntos Civiles y Causas Penales - Bundesgerichtshof, con sede en Karlsruhe-; el Tribunal Supremo Federal para Asuntos Sociales — Bundessozialgericht, con sede en Kassel—; el Tribunal Supremo Federal para lo Administrativo - Bundesverwaltungsgericht, con sede en Leipzig_-; el Tribunal Supremo Federal para Asuntos Fiscales —Bundesfinanzhof, con sede en Munich-; y el Tribunal Supremo Federal de Trabajo — Bundesarbeitsgericht, con sede en Erfurt. Cito las ciudades sede para que se retenga la diversificación del mismo en diferentes tribunales con diferentes lugares, y no un único tribunal compuesto de diversas salas, y se aprecie la facilitación del acceso a todos los ciudadanos alemanes repartiendo sus sedes, evitando que haya ninguno de ellos en la capital política de la república (Berlín). La razón de este «reparto territorial de sedes» puede estar, entre otras, en favorecerse así mejor la independencia judicial. Consúltese WoLF, M., Gerichtsverfassungsrecht aller Verfahrenszweige (6. ed.), C.H. Beck, München 1987, p. 91. Todo un modelo de descentralización judicial y al máximo nivel.

42 Se trata de los Amtsgerichte, Landsgerichte y Oberlandesgerichte, es decir, por equivalencia con España más o menos acertada, jueces civiles y penales (de primera instancia), audiencias provinciales (de apelación) y tribunales superiores de justicia, $\$ 12$ de la Ley Orgánica de los Tribunales, cit. Vide Gómez CoLOMER, J.L., El proceso penal alemán. Introducción y Normas Básicas, Bosch, Barcelona 1985, pp. 55 y ss.

43 GonzÁlez Beilfuss, M., Los tribunales constitucionales de los Länder alemanes, en Revista Autonomies 1996, n. $^{\circ} 21$, pp. 1 y ss.

44 La Gerichtsverfassungsgesetz (Ley Orgánica de los Tribunales — GVG), cit., de 12 de septiembre de 1950, últimamente modificada en 2019. Aunque sea un libro antiguo y, por tanto, con muchas reformas legales posteriores, puede consultarse Witthaus, R.E., Poder Judicial alemán, AdHoc, Buenos Aires 1994, pp. 61 y ss.

45 Deutsches Richtergesetz (DriG), de 8 de septiembre de 1961, últimamente modificada en 2015.

46 Perron, W., La Administración de Justicia en Alemania, en Pedraz Penalva, E., «En torno a la designación de los Vocales del Consejo General del Poder Judicial a la luz del Estado de Derecho», cit., pp. 53 a 56. Véanse los arts. 60.1 y 98.4 de la Grundgesetz; y $\$ \$ 2$ a 4 y 9.2 de la Ley de Elección de Jueces (Richterwablgesetz-RiWG), de 25 de agosto de 1950, últimamente modificada en 2015. 
Este sistema sería absolutamente criticable si no fuera porque la formación, la preparación, en suma, la calidad técnico-jurídica de los jueces alemanes está fuera de toda discusión, dado el sistema de acceso a la misma, de una dificultad y complejidad sin igual en Europa. ${ }^{47}$ Con lo cual daría igual que nombrase el ministro, pues la independencia nunca estaría, en principio, en peligro.

Salvo que se considere como tal a la Comisión de Elección Judicial citada, no hay equivalente en Alemania a nuestro Consejo General del Poder Judicial. ${ }^{48}$

\section{LA CRÍTICA REAL A LA POLITIZACIÓN DEL CONSEJO, ¿ES RESPONSABLE LA CONSTITUCIÓN DE ELLO?}

Cuando se afirma que nuestro Consejo General del Poder Judicial está politizado, afirmación que corrobora la inmensa mayoría de la doctrina citada en este artículo, independientemente de la crítica política que cualquier ciudadano puede hacer en un país libre en todo momento, ${ }^{49}$ a veces carente de todo fundamento, se piensa en dos cuestiones muy concretas para fundar esa opinión: Reducción de competencias y control sobre el nombramiento de sus miembros.

En cuanto a las competencias, y desde 1985, se observa una clara línea operativa consistente en reducir las atribuciones del CGPJ devolviéndoselas al Ministerio de Justicia, dejando para el CGPJ sólo las que son citadas literalmente por la Constitución. Recuerdo que las funciones fijadas en la Constitución son exclusivamente: Nombramientos, ascensos, inspección y régimen disciplinario. Es decir, estamos ante el desapoderamiento aludido supra, pero al revés, desapoderamiento del Poder Judicial. ${ }^{50}$ No diré más sobre el tema para no alejarnos de

47 Consecuencia de la dureza de los estudios universitarios en Alemania. Véase Carro FernánDeZ-Valmayor, J.L., Polémica y reforma universitaria en Alemania (libertad científica, cogestión, numerus clausus), Ed., Madrid, 1976, passim. Véanse complementariamente los $\S 5$ a 7 de la Ley Judicial Alemana (Deutsches Richtergesetz - DriG), cit.

48 El CGPJ podría servir como modelo para una posible introducción futura en Alemania de la institución, v. Perron, W., Der spanische Consejo General del Poder Judicial — «Selbstregierungsorgan der richterlichen Gewalt«, Deutsche Richterzeitung-DriZ 1983, November, p. 432.

49 No es ni siquiera un tema colateral en este estudio, pero la afirmación no es carente de fundamento. En los primeros 25 años de existencia del Consejo, la opinión negativa, una institución en penumbra dice el informe, la recogen Toharia Cortés, J.J. / García de la Cruz Herrero, J.J., La Justicia ante el espejo: 25 años de estudios de opinión del CGPJ, CGPJ, Madrid 2005, pp. 48 a 57. Hoy, en 2019, uno de cada 3 españoles piensa que la justicia funciona mal; uno de cada 4 cree que la justicia está politizada; uno de cada 2 cree que la Justicia funciona mal y que existe el Consejo General del Poder Judicial, pero ninguno conoce sus competencias. Fuente: CIS julio 2019. Ello es tan significativo que es noticia de prensa, v. https://www.europapress. es/nacional/noticia-cada-espanoles-piensa-justicia-funciona-mal-atribuye-penas-blandas-20190730160045. html.

50 La doctrina lo ha destacado unánimemente. Véanse, por ejemplo, Alzaga Villaamil, Ó., Discursos parlamentarios (y otras disertaciones), Marcial Pons, Madrid 2019, pp. 286 y 287; Cavero Lataillade, I., en Alzaga Villaamil, Ó. (Dir.), Comentarios a la Constitución española de 1978, cit., pp. 483 y ss.; Andrés 
nuestro objeto principal, ${ }^{51}$ pero a la vista de estas pérdidas competenciales el Consejo parece un órgano vacío y sin sentido. ${ }^{52}$

Voy al segundo punto, al control de los nombramientos de los miembros del CGPJ, concentrando el poder en manos del Gobierno, estableciendo un sistema de nombramiento de vocales en el que el partido mayoritario designa, a través de las Cortes, a todos los que pueda de su «sensibilidad». ${ }^{53}$

Es decir, volver a un control de los jueces y magistrados, no similar al que se dio durante la época franquista, pues en nuestra democracia ello sería imposible, sino a un control propio de lo que muy sutilmente se considera el reflejo de la mayoría parlamentaria, conforme a la cual todos los poderes del estado deben responder al esquema de gobierno registrado tras unas elecciones generales democráticas, de manera que Parlamento, Gobierno-Ejecutivo-Administración y Gobierno del Poder Judicial respondan al menos a la misma proporcionalidad en cuanto a su composición. Esto se ha traducido en nuestra realidad práctica desde 1985 en que la mayoría de los Vocales del Consejo General del Poder Judicial deben ser propuestos en el momento de su renovación por el partido que gobierna (obviamente en forma consensuada con la oposición, pero reservándose la mayoría), en definitiva, en que el Gobierno tenga el control del Poder Judicial. ${ }^{54}$

Pues bien, de ninguno de estos dos aspectos trascendentales de la politización es responsable nuestra Constitución. La aprobación de la Ley de 1980 lo demuestra. Culpables, si los hubiere, serían quienes juegan a la representatividad proporcional en los tres poderes del Estado, es decir, los gobiernos de turno (quienes los proponen), los parlamentarios (diputados y senadores que los votan) y los

Ibáñez, P. / Movilla Alvárez, C., El Poder Judicial, Tecnos, Madrid 1986, p. 76; Montero Aroca, J., Independencia y responsabilidad del Juez, cit., p.131; y GonZÁLEZ GrANDA, P., Independencia del juez y control de su actividad, Tirant lo Blanch, Valencia1993, p. 144.

51 Analiza con detalle las variaciones competenciales del CGPJ en 1980 y 1985, BALLeSTER CARDELL, M., El Consejo General del Poder Judicial. Su función constitucional y legal, cit., pp. 195 a 201, y 212 a 239. Es cierto que la Ley Orgánica 16/1994, de 8 de noviembre, por la que se reforma la Ley Orgánica 6/1985, de 1 de julio, del Poder Judicial, otorgó al CGPJ competencias en materia de selección y formación de los jueces, amplió sus facultades consultivas y en cierta medida la potestad reglamentaria, pero fue claramente una reforma insuficiente por sus limitaciones.

52 A la vista de esta reducción competencial, políticamente se ha llegado a proponer a finales de 2015 la supresión del CGPJ por el Partido Ciudadanos (v. https://elpais.com/politica/2015/11/07/actualidad/1446884889_172099.html); o un cambio drástico en el procedimiento actual de nombramiento, v. Propuesta unitaria de las asociaciones judiciales «LA JUSTICIA NO PUEDE SEGUIR SIENDO LA GRAN OLVIDADA», de 17 de diciembre de 2015, firmada por la Asociación Profesional de la Magistratura, la Asociación Judicial Francisco de Vitoria, Jueces para la Democracia y el Foro Judicial Independiente, punto 3. Últimamente, el Grupo Parlamentario Confederal de Unidas-Podemos ha formulado una Proposición de Ley para derogar la LO 4/2013, volviéndose a la situación legal anterior (v. BOCG. CD, Serie B, 1 de diciembre de 2017, n. $\left.{ }^{\circ} 181-1\right)$.

53 Véase Ballester Cardell, M., El Consejo General del Poder Judicial. Su función constitucional y legal, cit., pp. 295 a 299.

54 Se ha entendido que el sistema de nombramientos de los Vocales podría violar el punto 27 de la Recomendación CM/Rec(2010)12 del Comité de Ministros del Consejo de Europea, a consultar en lengua inglesa en https://rm.coe.int/16807096c1. 
propios vocales y presidentes designados (quienes aceptan el juego), olvidando que el Poder Judicial es un poder en el que su democratización no responde generalmente bien al sistema del voto (nadie con peso y auctoritas propone en la Unión Europea con seriedad y rigor que los jueces sean elegidos públicamente por los ciudadanos en una votación). ${ }^{55}$

La Constitución quiso algo muy claro, especialmente sensible para romper con la dictadura anterior y determinante para el nuevo sesgo de la Justicia en España: Lograr una independencia judicial verdadera, y para conseguirlo, creó el Consejo General del Poder Judicial, su máximo defensor. Pero para entenderlo correctamente, hay que conocer el entorno también. ${ }^{56}$

1. $\left.{ }^{\circ}\right)$ Constitución e independencia: El entorno es la configuración político-territorial del Reino de España: Un Estado central compuesto de Autonomías periféricas. Así es. Una de las decisiones más importantes que tuvo que adoptar la clase política española en el tránsito de la dictadura a la democracia (1975-1978) fue la de reconocer explícitamente y encauzar en un nuevo modelo de Estado los territorios españoles. Esta última decisión se tradujo en la reserva en la Constitución democrática de 1978 de todo un título (Título XVIII, artículos 137 a 158), dedicado a la nueva configuración política de los territorios que unidos conforman España, que pasaron a denominarse «comunidades autónomas» (17 comunidades autónomas en total, más dos ciudades autónomas), sin perjuicio de otras disposiciones dispersas en la propia Constitución que hacen referencia jurídico-política a ellas.

El pensamiento fundamental del legislador constituyente fue que la comunidad autónoma se tradujera desde el punto de vista organizativo en un reflejo del Estado, si no idéntico, al menos bastante parecido, autorizando en ella la constitución de un poder legislativo y de un poder ejecutivo propios (artículo 152 de la Constitución). No quiso sin embargo que se cumpliera cabalmente la división de poderes de Montesquieu, porque las comunidades autónomas no tienen un poder judicial propio. El poder judicial en España es único (artículo 117.5 de la Constitución).

¿Por qué no quiso el legislador constituyente español en 1978 que las comunidades autónomas pudieran tener un poder judicial propio ${ }^{57}$

55 Los peligros de parcialidad, corrupción y populismo son más que evidentes. Algunos estados de Estados Unidos, por un lado, y algunas naciones de América Latina (sólo Bolivia), no son ejemplos válidos de elección popular de los jueces para nuestra Europa democrática. Sólo se admite en los Juzgados de Paz. La selección del Jurado no es un método electoral.

56 En este epígrafe IV de este artículo resumo a partir de ahora muy apretadamente unas ideas propias expuestas en Gómez Colomer, J.L., Independencia judicial y diseño político del Estado, en Juan-Luis Gómez Colomer / Silvia Barona Vilar / Pía Calderón Cuadrado (coord.), «El Derecho Procesal español del siglo xx a golpe de tango. Juan Montero Aroca. Liber Amicorum, en homenaje y para celebrar su LXX cumpleaños», Tirant lo Blanch, Valencia 2012, pp. 339 a 362. Me remito a este lugar para una más extensa fundamentación.

57 No olvidemos que negar dicho poder en la comunidad autónoma fue un hecho indiscutido en su momento y que la amplísima mayoría que obtuvo el Sí en el referéndum del día 6 de diciembre de 1978 (más del $88 \%$ de los votantes), demuestra indubitadamente que eso era lo que querían los españoles, 
En mi opinión, la razón fundamental por la que se estimó no conveniente la existencia de un poder judicial propio en las comunidades autónomas no fue ni jurídica, ni de otra índole, v.gr., económica o social, sino política, sólo que con enormes consecuencias jurídicas. La razón política está unida a la decisión, también constitucional, de que España fuese y sea un estado no federal, sin ser tampoco un estado centralista, sino un estado intermedio avanzado, un estado con autonomías. La innovación que suponía esta nueva vía política, implicó tomar decisiones excluyentes en su momento, siendo la principal la concepción unitaria del estado en la configuración de su poder judicial.

Pero ello sólo explica la forma y no el fondo de la cuestión. Aceptándose que la razón por la que el diseño constitucional excluyó al poder judicial autonómico fue por pensarse que los tribunales propios de las autonomías no encontraban acomodo en un estado no federal, modelo que políticamente fue desechado, la pregunta esencial sigue en pie: ¿Por qué se excluyó sólo al poder judicial, y no a cualquiera de los otros dos, o a los dos rebajándose la calidad del gobierno?

Las CCAA, en mi modesta opinión, no disponen de un poder judicial propio porque en España, después de una larga dictadura, se pensó, en el momento histórico de la transición democrática y elaboración de nuestra constitución actualmente vigente, que era la decisión más apropiada para garantizar la independencia judicial, absolutamente necesaria para lograr cuanto antes la plena democratización..$^{58}$

La independencia judicial es claramente un principio político de naturaleza jurisdiccional orgánica en una democracia, sin duda alguna, pero no es una cuestión territorial, ni de un estado ni de un territorio de ese estado, sino un pilar básico para que el proceso sea justo (fair), se celebre en donde se celebre y se desarrolle, en cualquiera de sus fases, en donde se desarrolle. La forma del estado no es lo importante. El único presupuesto para que su aplicación sea plenamente eficaz es que el estado sea una democracia. ${ }^{59}$

Por tanto, la cuestión esencial es que, sin independencia judicial, ni puede existir un proceso debido, un proceso justo, o un proceso con todas las garantías, ni puede existir un verdadero poder judicial, ni en definitiva puede desarrollarse la propia democracia.

La cuestión central para mí entonces es determinar si es admisible que la decisión de que las CCAA no tengan un poder judicial propio, obedece a la idea

independientemente de detalles en que se pueda discrepar legítimamente. Lo esencial de la propuesta de Constitución, y por tanto la inexistencia de poderes judiciales autonómicos, fue aceptado como tal sin discusión.

58 Lo que ciertamente ha acabado significando, por otra parte, una auténtica supremacía del poder judicial sobre los otros poderes del estado, v. Hernández MARTín, V., Independencia del Juez y desorganización judicial, Civitas, Madrid 1991, p. 56.

59 No debe olvidarse que en origen la independencia judicial fue uno de los muchos postulados antimonárquicos y revolucionarios de principios del siglo XIX. En este orden SimON, D., La independencia del Juez, cit., pp. 9 a 11. 
de que sólo el estado es capaz en estos momentos de garantizar la independencia judicial. Ésa es la opción que en su momento se consideró la mejor para garantizarla.

Pero no sólo se configuró el principio de la unidad jurisdiccional con ese fin, sino que también derivadamente se articuló en nuestra norma suprema igualmente un Poder Judicial único, una organización judicial única para todo el Estado, un estatuto jurídico común para todos los jueces y magistrados y, además, un catálogo de garantías concretas de la independencia judicial, entre las que debe destacarse especialmente la inamovilidad, en donde reside una de las claves esenciales, razón por la que tiene fundamento constitucional en España igualmente (art. 117.1) ${ }^{60}$.

Esto es posible entre otras cosas porque la Constitución tomó paralelamente la decisión de que la legislación procesal orgánica, y también la procesal civil y procesal penal, fuese de competencia exclusiva del Estado (art. 149.1-5. ${ }^{\mathrm{a}}$ y $6 .^{\mathrm{a}}$ ), ${ }^{61}$ de manera que las comunidades autónomas no pudiesen legislar sobre esta materia, con la salvedad que mencionaremos enseguida.

En la unidad jurisdiccional reside pues la clave de bóveda de todo el sistema para garantizar que se sostiene, para garantizar la independencia judicial.

En la propia elaboración de la Constitución resultó evidente, sin embargo, que negar a las comunidades autónomas un Poder Judicial propio no iba a resultar en lo político absolutamente indiscutido y asumido por todos sin rechistar ${ }^{62}$. Por eso el propio texto constitucional fijó en diferentes preceptos un mínimo de participación de las comunidades autónomas en la organización del Poder Judicial, que no en el ejercicio de la potestad jurisdiccional. El problema es que lo ha hecho de tal manera que, en vez de fijar la posición política de manera clara e irrefutable, ha sembrado tales dudas, incluso contradicciones, que ha abierto sin desearlo nuevas vías polémicas para mantener viva la llama sin cerrar el interrogante, que las comunidades autónomas, mucho más atentas que el estado, han aprovechado hábilmente. Por eso se ha forzado a que el máximo intérprete de nuestra Constitución, el Tribunal Constitucional, tome partido al firmar decisiones que no debería haber adoptado nunca, creando todavía más polémica. La última de ellas sobre el tema será objeto de una consideración especial infra.

60 La inamovilidad de los jueces se consagró teóricamente en España en 1870 con la Ley provisional sobre Organización del Poder Judicial. Vide FAIRÉn GuIllén, V., La independencia judicial en España en la actualidad, cit., tomo I, p. 81.

61 Su interpretación literal tampoco fue pacífica al discutirse que el Estado fuera centralista sólo en lo judicial, v. Andrés Ibáñez, P. / Movilla Alvárez, C., El Poder Judicial, Tecnos, Madrid 1986, p. 250.

62 El ilustre Magistrado de la Corte Suprema Federal de los Estados Unidos de Norteamérica entre los años 1932 y 1938 Benjamín Nathan CARDozo, nos pone la cita ejemplar al alcance de la mano: «La prohibición de Justiniano de hacer cualquier comentario sobre lo producido por sus codificadores se recuerda sólo por su inutilidad». Vide Cardozo, B.N., La función judicial (trad. Victoria Cisneros y Leonel Pereznieto Castro), Pereznieto, Atizapán de Zaragoza (México) 1996, p. 5. 
2. ${ }^{\circ}$ ) Constitución, Consejo General del Poder Judicial e independencia judicial: Para redondear la estructura organizativa, hemos dicho que la Constitución consagró también un órgano autónomo multifuncional, pero especialmente diseñado para lograr una práctica efectiva de la independencia judicial, el Consejo General del Poder Judicial (art. 122), único para todo el estado igualmente.

Pues bien, respecto al principio de la independencia judicial, me parece claro que el diseño que se articula en nuestra Constitución es el siguiente: En su vertiente subjetiva o interna, la independencia es un principio personal de todos los jueces y magistrados de España en el ejercicio de la función jurisdiccional cumpliendo las leyes, que se protege, también personalmente, mediante el establecimiento de ciertas garantías (inamovilidad básicamente); en su vertiente objetiva o externa, se crea el Consejo General del Poder Judicial para que, como órgano de autogobierno, proteja institucionalmente a todos los jueces y magistrados frente a los demás poderes del Estado, en particular, frente a intromisiones del poder ejecutivo, ayudado del Ministerio fiscal, otro órgano constitucional, quien debe velar por la independencia de los tribunales según la propia Constitución.

El estado es, pues, el único garante de la independencia judicial en la actualidad política española así entendida, y las comunidades autónomas ningún papel pueden jugar en ello.

3. $\left.{ }^{\circ}\right)$ Constitución y realidad actual: Pero la realidad nos ha mostrado varias veces que este diseño no es ya aceptable, ha quedado anticuado, al menos para las comunidades autónomas más exigentes, porque han dejado de aceptar el principio de la unidad jurisdiccional y su razón de ser tal y como han sido formulados y diseñados en la Constitución. Si no todas, al menos dos de las más importantes, País Vasco y Cataluña.

La lucha por adquirir mayores cotas de autonomía en materia de Poder Judicial se ha focalizado en dos grandes vías, claramente diferenciadas, pero perfectamente complementarias entre sí: Aprobación, desarrollo y reforma de los estatutos de autonomía propios (vía estatutaria), y recurso de inconstitucionalidad ante el Tribunal Constitucional, principalmente (vía judicial).

1. Vía estatutaria: Desde los primeros estatutos de autonomía aprobados se puede decir que las comunidades autónomas respetaron en los años 80 el límite constitucional máximo, ocupándose en lograr mayores cotas de autonomía en temas puntuales: $\left.1^{\circ}{ }^{\circ}\right)$ Las comunidades autónomas han exigido progresivamente más competencias de los Tribunales Superiores de Justicia;.$^{\circ}$ ) Han exigido cada vez con mayor fuerza el cumplimiento de determinados requisitos en los magistrados que sirven en tribunales insertados en ellas ${ }^{63} ;$ y $\left.3 .^{\circ}\right)$ Han exigido progresivamente también que los órganos y procedimientos de la llamada Justicia alternativa fueran propios;

63 Gómez Colomer, J.L., Politica autonómica y Poder Judicial (Análisis de la problemática en Galicia), Revista Vasca de Administración Pública 1.989, n. ${ }^{\circ} 24$ (mayo-agosto 1989), p. 73. 
2. Vía judicial: La segunda modalidad que han encontrado las Comunidades Autónomas para lograr la expansión a que nos referíamos ha sido, forzadas en la mayor parte de los casos por el control estatal de sus normas propias, el recurso de inconstitucionalidad ante el Tribunal Constitucional. Unas veces se ha discutido sobre ello al hilo de las cuestiones de competencia, otras al hilo de verdaderos temas de fondo. ${ }^{64}$

Me fijaré más bien en el fondo, es decir, en el contenido de los recursos de inconstitucionalidad y de las sentencias que han provocado, porque creo que aquí está el meollo actual de la cuestión. ${ }^{65}$ De ellos destaco el intento de apropiación de órganos constitucionales para trasladarlos a su órbita política, restando competencias del estatal en favor de su órgano equivalente autonómico. El caso más relevante es el de los Consejos de Justicia Autonómicos ${ }^{66}$.

Aunque no todos siguen el mismo modelo, la idea central ha sido que estos consejos puedan asumir en la comunidad autónoma todas las competencias o las máximas posibles que para el autogobierno del poder judicial se han concedido estatalmente al Consejo General del Poder Judicial, algo muy difícil de explicar desde el punto de vista del principio de la unidad jurisdiccional, ${ }^{67}$ porque ciertas competencias del Consejo General del Poder Judicial únicamente las puede tener él constitucionalmente, las que afectan al estatuto jurídico de los miembros del Poder judicial específicamente (art. 122.1) ${ }^{68}$

64 No entraré sin embargo en la primera de las modalidades, porque generalmente se ha tratado de discusiones competenciales que han ido fijando paulatinamente la extensión y límites de los arts. 148 y 149 de la Constitución.

65 No haré un repaso de la jurisprudencia constitucional, que debe partir esencialmente de sus Sentencias 56/1990, de 29 de marzo y 62/1990, de 30 de marzo, y algunas otras posteriores, como la Sentencia 247/2007, de 12 de diciembre, sobre el Estatuto valenciano, sino que me centraré tan sólo en la última de ellas que aborda las competencias del CGPJ y sus nombramientos, la polémica Sentencia 31/2010, de 28 de junio sobre el texto del nuevo Estatuto de Cataluña de 2006, que ha decido cuestiones muy relevantes sobre el Poder Judicial y ha fijado una sólida doctrina en varios aspectos.

66 Citemos el Consejo Judicial Vasco de la Propuesta de Estatuto Político de la Comunidad de Euskadi de 2003 (art. 27); el Decreto 119/2002, de 16 de abril, por el que se crea al Consejo de Justicia de Cataluña, previsto posteriormente en el nuevo Estatuto de Autonomía de Cataluña de 2006 (arts. 97 a 100); el Consejo de la Justicia de la Comunidad Valenciana (art. 33.3 del nuevo Estatuto de Autonomía de la Comunidad Valenciana de 2006, aprobado por Ley Orgánica 1/2006, de 10 de abril), y el Consejo de Justicia de Andalucía (art. 141 del Estatuto de Autonomía de Andalucía, aprobado por la Ley Orgánica 2/2007, de 19 de marzo). No obstante, en tanto en cuanto, respetando la Constitución, fueran órganos auxiliares o instrumentales del CGPJ, representando foros limitados territorialmente de reflexión y debate sobre la Justicia, serían constitucionales y admisibles. Otra pregunta sería si, aun con ello, serían útiles y necesarios. Véase BALLESTER CARDELL, M., El Consejo General del Poder Judicial. Su función constitucional y legal, cit., pp. 326 a 332.

67 Pero, aun así, se intenta, porque el Consejo de Justicia es más vulnerable que el juez desde la órbita de la independencia, es más fácil controlarlo políticamente, v. GonZÁLEZ GrANDA, P., Independencia del Juez y control de su actividad, Tirant lo Blanch, Valencia 1993, p. 139.

68 Estos consejos iban a tener una base orgánica vigente para toda España, pues ya fueron propuestos en el Libro Blanco de la Justicia, elaborado por el Consejo General del Poder Judicial en 1998 (Capítulo sexto, apartado III, g), y diversos proyectos de reforma de la Ley Orgánica del Poder Judicial y de la Ley de Planta y Demarcación Judiciales (en 2005 y en 2009) habían previsto las normas mínimas, pero ninguno de ellos se acabó convirtiendo en ley vigente por cuestiones políticas. La doctrina, en general, los consideraba hasta hace 
El Tribunal Constitucional ha fijado la que de momento es doctrina constitucional, muy formal, poco profunda en cuanto al fondo, sobre los consejos de justicia autonómicos, al hilo de su Sentencia 31/2010, de 28 de junio, cit., sobre el nuevo Estatuto de Autonomía de Cataluña de 2006, analizando en particular la constitucionalidad del Consejo de Justicia de Cataluña.

En esencia, los arts. 97 a 100 de dicho Estatuto, según sus redactores dentro del más absoluto respeto a la Constitución, quisieron articular un Consejo de Justicia catalán, que tuviera prácticamente las mismas atribuciones que el Consejo General del Poder Judicial. La citada Sentencia 31/2010, de 28 de junio falló la inconstitucionalidad de varias de las normas dedicadas a ello, desnaturalizando absolutamente la propuesta autonómica.

Formalmente, el Tribunal Constitucional basó la inconstitucionalidad de estas normas estatutarias en el entendimiento de que se infringía la reserva de ley orgánica que hace el art. 122 de la Constitución, es decir, que estos temas únicamente podían ser regulados por la Ley Orgánica del Poder Judicial, ${ }^{69}$ no sin discrepancias internas. ${ }^{70}$

Estos argumentos pasaron sin embargo por encima de la principal razón, de fondo, para declarar la inconstitucionalidad de esta propuesta: La vulneración del principio de la unidad jurisdiccional y, como consecuencia de ello, del principio de la independencia judicial, que implica la creación de un Consejo de Justicia sustituto para una parte del Estado del Consejo General del Poder Judicial, previsto por la Constitución precisamente para todo el Estado.

En mi opinión, la cuestión verdaderamente importante en todos estos movimientos e intentos por parte de los poderes políticos autonómicos ha sido controlar, en la mayor extensión posible, a nivel autonómico la Justicia, el Poder

bien poco inviables o innecesarios. Pero de lege ferenda la configuración era clara: Órganos de gobierno del Poder Judicial en el ámbito autonómico, dependientes y subordinados al Consejo General del Poder Judicial. Ahora se están moviendo las cosas por otros ámbitos, pues se está proponiendo la creación de Consejos Judiciales autonómicos muy distintos, en unos casos no se sabe muy bien por quién, v. https://www.elconfidencialdigital.com/articulo/politica/desconcierto-sector-judicial-propuesta-creacion-cgpjsautonomicos/20190809122746129560.html, y en otros previsoramente, v. el art. 55.2 del borrador de proyecto de reglamento de la Fiscalía (https://www.mjusticia.gob.es/cs/Satellite/Portal/1292429192590?blobheader $=$ application $\% 2 \mathrm{Fpdf} \&$ blobheadername $1=$ Content - Disposition\&blobheadervalue $1=\operatorname{attachment} \%$ 3B+filename\%3DProyecto_de_Real_Decreto_por_el_que_se_aprueba_el_Reglamento_del_Ministerio_ Fiscal.PDF). ¿No estaremos multiplicando los problemas de uno por 17, con riesgo extremo de acabar politizando absolutamente toda la Justicia española?

$69 \mathrm{Al}$ parecer la única razón suficiente para Muñoz Machado, S., Dentro de los términos de la presente Constitución, revista El Cronista del Estado Social y Democrático de Derecho 2010, n. ${ }^{\circ}$ 15, p. 7.

70 Los votos particulares a la sentencia, complementariamente, han entendido que por estos argumentos formales y las consecuencias que se derivan de ellos, el Tribunal Constitucional ha ido mucho más allá de sus funciones, transformándose siendo un órgano judicial en un órgano legislativo, porque ha decidido sin autorización, en vez de limitarse a declarar la inconstitucionalidad del Consejo catalán, que dicho órgano sea constitucional en lo salvado por la sentencia y se convierta así en un órgano de la Generalitat. Vide voto particular a la Sentencia del Tribunal Constitucional 31/2010 del Magistrado Javier Delgado Barrio, apartados 1, A) у C) у 11, B). 
Judicial, es decir, en quitarle al Estado lo que la Constitución le da, sin preocupación alguna por el flagrante ataque al principio de la unidad jurisdiccional, que ello suponía, sustituyéndolo por otro principio idéntico o similar pero de aplicación en el territorio de la comunidad autónoma, algo hoy incompatible con nuestra Constitución como con acierto ha dicho el Tribunal Constitucional ${ }^{71}$.

Poniendo en peligro de esta manera dicho principio, la independencia judicial no estaba en serio riesgo, sino en segura quiebra, porque lo que pienso que motiva dicho ataque, en el que el agresor debería saber claramente que está vulnerando la Constitución, dicho con toda prudencia, es querer controlar políticamente a los jueces que desarrollan su función en el territorio de la comunidad autónoma de alguna manera, control que se quiere incluso que llegue al lugar de nacimiento. La existencia de diversos consejos autonómicos quebraría el deseo constitucional de que la carrera judicial sea única, y con ello se pondría en peligro el principio de la independencia judicial, porque éste se halla garantizado básicamente por esa unidad, sin duda alguna en el momento actual en España con el texto constitucional en la mano. ${ }^{72}$

Es cierto que nada nuevo hay bajo el sol en este tema, pues también el poder político central, el español, ha realizado numerosos intentos de controlar al poder judicial, algunos de ellos con éxito, con lo que el poder político central no es menos inocente por ello que el poder autonómico. El ejemplo aquí tratado del nombramiento de los magistrados de los tribunales más elevados de España es más que suficiente. ${ }^{73}$

La pugna entre la derecha y la izquierda políticas en España sobre el Poder Judicial no es tan distinta ni tan extraña como pudiera parecer. Las reformas legales en materia de Poder Judicial demuestran que ambos sectores cuando han gobernado quieren lo mismo, controlar al Poder Judicial. ${ }^{74}$

71 La Justicia como gran pagana del movimiento reformatorio, v. ReQuejo IbáñeZ, J.L., Comunidades Autónomas y Administración de Justicia, en «La reforma de los Estatutos de Autonomía», Revista Jurídica de Castilla y León 2003, p. 617.

72 Véase en esta línea Prego de Oliver Tolivar, A., El Poder Judicial y la construcción del Estado autonómico, en Aguiar de Luque, L. / Prego de Oliver Tolivar, A. / Xiol Ríos J.A., «La justicia ante la reforma de los Estatutos de Autonomía», Centro de Estudios Jurídicos — Aranzadi, Cizur Menor (Navarra) 2005 , pp. 85 y 86.

73 Los escándalos que se producen en particular cada vez que el Consejo General del Poder Judicial tiene que nombrar a un nuevo magistrado de cualquier Sala, especialmente de la Sala II del Tribunal Supremo (la que de verdad controla para bien o para mal al Gobierno gracias al privilegio, claramente vulnerador del principio de igualdad, del aforamiento), son vergonzosos a los ojos de cualquier jurista decente. Me remito a Igartua Salaverria, J., «Designación de vocales del consejo general del poder judicial», Revista vasca de derecho procesal y arbitraje — Zuzenbide prozesala ta arbitraia euskal aldizkaria, 2002, vol. 14, n. ${ }^{\circ}$ 3, pp. 684 y ss.; y a Gómez Colomer, J.L., Privilegios procesales inconstitucionales e innecesarios en la España democrática del siglo XXI: El sorprendente mantenimiento de la institución del aforamiento, en Revista Teoría y Realidad Constitucional 2016, n. ${ }^{\circ} 38$, p. 239 y ss. Sobre un caso concreto en el que el procedimiento de nombramientos muestra todos sus defectos, esta vez para la Sala I, v. Igartua Salaverria, J., La motivación de los nombramientos para Magistrados por el 5. ${ }^{\circ}$ turno, Revista Vasca de Administración Pública 2019, n. ${ }^{\circ} 113$, pp. 85 y ss.

74 Claro, lo pretenden guardando las formas, reformando democráticamente las leyes, contando con ciertos consensos populares y profesionales, en fin, con justificaciones suficientes a su entender para avalar los 
Pues bien, si el órgano contaminado es el Consejo General del Poder Judicial, del que se dice en círculos jurídicos muy bien informados y de gran prestigio que está políticamente muerto ${ }^{75}$, porque tan sólo se dedica hoy al tema disciplinario, sin que se pueda impedir la injerencia política en el nombramiento de los jueces, y sin autonomía para decidir la política judicial, lo que habrá que hacer es resucitarlo, porque es un órgano constitucional que deben cumplir una función. Existe al parecer acuerdo político en ello, pero nadie le ha puesto todavía el cascabel al gato.

El problema es que habría que reformar la Constitución, en éste y en otros temas, y mientras no se reforme poco se podrá hacer, a nivel estatal y a nivel autonómico. Esto no es sin embargo sólo una cuestión jurídica, sino que es ante todo política, pues afecta a la configuración del Estado, y a ver qué político con posibilidades se atreve a proponer esto hoy en día en España. ${ }^{76}$

Sea como fuere, mientras no se opte por una u otra vía, las cosas tienen que seguir, como ha dicho el máximo defensor de nuestra Constitución, el Tribunal Constitucional, como están, porque sólo él es quien puede decirlo jurídicamente con nuestra Constitución en la mano.

Juez independiente, en 1978 y en 2019, sigue siendo por tanto aquél que, en el ejercicio de su función jurisdiccional, a saber, juzgar y hacer ejecutar lo juzgado, está sometido al imperio de la ley, y sólo a ella. Éste es el juez que el Consejo General del Poder Judicial está obligado constitucionalmente a proteger.

\section{LOS AMPLIOS LÍMITES CONSTITUCIONALES NO FAVORECEN UNA SOLUCIÓN ÚNICA Y ACEPTABLE POR TODOS. ¿QUÉ SERÍA LO MEJOR?}

A la vista de lo expuesto, se constata que la CE quiso ser muy generalista, dejando claro que el CGPJ sustituía prácticamente en todo al Ministerio de Justicia

cambios en la política judicial que defienden. Pero lo que desean de verdad es tener la mayoría política en el Consejo General del Poder Judicial, para así poder tener la mayoría en los tribunales que por sus competencias pueden ser los más peligrosos para ellos políticamente, los que pueden controlar su actuación e incluso acabar políticamente con ellos al condenarles penal o administrativamente (Salas II y III del Tribunal Supremo, Audiencia Nacional y Tribunales Superiores de Justicia).

75 La afirmación es del propio Montero Aroca, en Montero Aroca, J. / Gómez Colomer, J.L. I Montón Redondo, A. / Barona Vilar, S., Derecho Jurisdiccional I, Parte General, cit., p. 137.

76 Pero no olvidemos las certeras palabras, con pleno significado en la actualidad también, de Thomas JEFFERSON, el ideólogo y revolucionario de la independencia norteamericana más importante y uno de los 39 Padres Fundadores del nuevo estado y redactores de la Constitución de 1787, cuando afirmó que «ninguna generación puede contraer deudas mayores que lo que pueda pagar en el transcurso de su propia existencia..., ninguna sociedad puede elaborar una constitución perpetua, ni aun una ley perpetua. La tierra pertenece siempre a la generación de los vivos..., una ley de duración limitada es mucho más fácil de gestionar que una que necesite una derogación...». Véase su Carta a James Madison, fechada en París el 6 de septiembre de 1789, recogida en Hardt, M., Thomas Jefferson. La Declaración de Independencia, Akal, Madrid 2009, pp. 117, 120 y 121. Sensatas palabras, que no hace falta actualizar demasiado. 
respecto a jueces y magistrados, que el procedimiento para designar sus miembros debía conducir a la designación de personas altamente cualificadas y que sólo quería un gobierno del poder judicial en España (ninguno autonómico).

Obviamente, diversos modelos al amparo del art. 122 CE eran y son posibles $^{77}$, y todos ellos pueden ser democráticos y respetuosos con la independencia judicial. ${ }^{78}$ También es verdad que todos los propuestos hasta la fecha han sido polémicos, como ha demostrado la realidad española. ${ }^{79} \mathrm{El}$ problema es que, como se ha visto, en España está ganando la tendencia pública a un control político de la composición del Consejo General del Poder Judicial por parte del poder de turno, lo que lleva a que sus miembros no siempre sean los mejores, y a que se le resten funciones y competencias, negándosele siempre la de elaborar su propio presupuesto. Como tampoco faltan intentos, antes aludidos, de copiar el modelo en las autonomías, se puede decir que las previsiones constituciones están siendo, sencillamente, vapuleadas. ${ }^{80}$

¿Cómo solucionar el gravísimo problema de la politización del CGP, que sería lo mejor? Con modestia, sólo veo dos posibilidades: Reformar la Constitución explicitando estrictamente las funciones y el procedimiento para los nombramientos de la manera más alejada posible al control político por el poder, o llegar a un nuevo gran acuerdo moral general por el que todos los políticos y demás intervinientes se obliguen a proponer para el Consejo General del Poder Judicial sólo a profesionales creyentes en la Justicia, intachables, competentes, valiosos, de trayectoria profesional incontestable, y con sentido de Estado, lo que afectaría especialmente a la propuesta sobre su Presidente.

Dejemos la primera, aunque seria y rigurosa jurídicamente, por ingenua, en el sentido que imaginar una reforma constitucional para este tema tan específico es algo impensable dada la complejísima situación política española en la actualidad. Pero una elevación del número parlamentario de votos exigidos para el nombramiento de los vocales favorecería, sin duda alguna, tener que apostar por la más alta cualificación de los designados y dejaría menos espacio al poder del partido mayoritario (por ejemplo, pasar de $3 / 5$ a 2/3, modificando el art. 122.3 $\mathrm{CE})^{81}$. Si a eso añadimos explicitar en la Constitución que el CGPJ tendría competencias plenas para todo lo judicial, el resultado sería muy satisfactorio.

$77 \mathrm{Y}$ todos constitucionales, siempre que no «resultasen arbitrarios o contradictorios con la naturaleza del Consejo» (FD 12 de la S TC 108/1986, de 26 de julio, cit.).

78 López Aguilar, J.F., La Justicia y sus problemas en la Constitución, Tecnos, Madrid 1996, pp. 117 y 118 .

79 Vide Cavero lataillade, I., en Alzaga Villaamil, Ó. (Dir.), Comentarios a la Constitución española de 1978, cit., pp. 491 y ss.

80 Y no afecta sólo al CGPJ, también a nuestro Tribunal Constitucional, al menos a la elección posterior a la primera constitución en 1980, v. Alzaga Villaamil, Ó., Sobre la composición del Tribunal Constitucional, Teoría y Realidad Constitucional (UNED) 2003, n. ${ }^{\circ}$ 10-11, p. 173.

81 Que es la proporción preferida en Alemania para los temas electorales que afectan al poder judicial (v. por ejemplo, el art. 98.2 Grundgesetz). 
Pero, desde el puro sentido común, me parece más factible la segunda posibilidad, es decir, no reformar la Constitución. Cuatro acciones podrían emprenderse:

1. $\left.{ }^{a}\right)$ Dotar al CGPJ de todas las competencias que afectan orgánicamente a la Justicia, desde el punto de vista judicial y auxiliar, lo que incluiría, sin entrar ahora en mayores detalles, la Oficina Judicial y sus componentes. Esas competencias afectarían fundamentalmente a garantizar efectivamente la independencia de los magistrados y jueces, al ejercicio de la potestad reglamentaria en temas judiciales internos, al control administrativo de la actuación judicial y del personal auxiliar mediante la potestad disciplinaria, a proponer su propio presupuesto, a controlar la legalidad, y a todas aquellas que comprendan la función de gestionar el Poder Judicial. ${ }^{82}$ Se trata, por tanto, de desapoderar totalmente al Poder Ejecutivo (Ministerio de Justicia) en favor del Poder Judicial, como quiso la Constitución y la Ley de 1980, para lo que únicamente es necesaria voluntad política, y sin que ello implique ni una sola desconsideración democrática, pues la elección permanece, sólo que no por un órgano político; ${ }^{83}$

2. $\left.{ }^{a}\right)$ Volver a la elección de los jueces por ellos mismos, como al principio (1980), articulando un sistema de elección directa verdaderamente democrático, controlado por el CGPJ saliente y no en función de cuotas de las asociaciones judiciales, previendo que en el resultado final haya tanto magistrados del Tribunal Supremo, como magistrados y como jueces, por ejemplo, en la proporción real de 1-4-7, que los jueces de instancia a elegir tengan una cierta experiencia mínima, por ejemplo 5 años, y que la promoción de su candidatura no dependa de la intervención de las asociaciones judiciales, sino que esté organizada neutralmente por el propio CGPJ saliente ${ }^{84}$

82 Vide Cavero lataillade, I., en Alzaga Villaamil, Ó. (Dir.), Comentarios a la Constitución española de 1978, cit., pp. 483 y ss.

83 Es dudoso que no sea democrático que el Parlamento no elija a los jueces. Vide Pedraz Penalva, E., En torno a la designación de los Vocales del Consejo General del Poder Judicial a la luz del Estado de Derecho, Tribunales de justicia: Revista Española de Derecho Procesal 1997, núms. 8-9, pp. 889 y 890; Pedraz Penalva, E., Del Consejo General del Poder Judicial y de la selección de sus miembros, en Pedraz Penalva, E., «En torno a la designación de los Vocales del Consejo General del Poder Judicial a la luz del Estado de Derecho», cit., pp. 20 y ss. Este autor parece proponer la creación de una Comisión Especial independiente. Un riesgo si no se garantiza que ésta sea verdaderamente independiente. Las conclusiones de las XXVIII Jornadas Nacionales de Juezas y Jueces Decanos de España, celebradas en Melilla, 15 a 17 de octubre de 2018, p. 12, a consultar en http://www.poderjudicial.es/cgpj/es/Poder-Judicial/En-Portada/Conclusiones-de-las-XXVIII-Jornadas-Nacionales-de-Juezas-y-Jueces-Decanos-de-Espana, proponen la elección directa. Con matices, v. SERRA Crisто́вAL, R., La elección de los miembros del Consejo General del Poder Judicial. Una propuesta de consejo más integrador e independiente, Teoría y Realidad Constitucional 2013, n. ${ }^{\circ} 31,2013$, pp. 277 y ss.

84 Se ha propuesto en 2018, mediante enmiendas del Partido Popular y de Ciudadanos a la reforma de la LOPJ, pero fueron rechazadas por el Congreso, v. https://confilegal.com/20181213-pp-y-ciudadanossacan-adelante-en-el-senado-la-reforma-para-que-los-jueces-elijan-a-los-vocales-del-cgpj/. 
3. $\left.{ }^{a}\right)$ Intentar llegar, respecto a los nombramientos por Las Cortes de vocales del CGPJ que no son jueces (juristas de reconocido prestigio), a un New Great Moral Deal. Sé que no es una cuestión jurídica y que ello plantea riesgos adicionales importantes (por ejemplo, ¿quién decide lo que es ajustado o no a la moral?). No me refiero tampoco a temas éticos internos. Para lo que se quiere resolver, hablar de transparencia y buen gobierno, o firmar unos Principios de Ética Jurídica, de nada sirve. Aquí se trata de elegir a los mejores profesionales, ${ }^{85} \mathrm{y}$

$4^{\circ} .^{\circ}$ Finalmente, en cuanto al Presidente del Tribunal Supremo electo por el CGPJ, que será su Presidente, sería importante establecer algún requisito adicional de idoneidad, más allá del art. 586 LOPJ vigente. Ser Magistrado del Tribunal Supremo (excluyendo a los demás juristas), con más de 25 años en activo sin interrupciones en el Poder Judicial y más de 10 años de servicios continuados en dicho Alto Tribunal, no haber pertenecido nunca a ningún partido político, no ser miembro de ninguna asociación judicial o habiéndolo sido no haber ostentado en ella cargo alguno, no haber sido nunca condenado por prevaricación, ni por delitos de corrupción u otros que hagan incompatible moralmente el cargo, como delitos contra la Constitución, contra los derechos fundamentales o de violencia de género, y acreditar saber hablar, leer y escribir dos lenguas europeas extranjeras con fluidez, podrían ser algunos ejemplos de ello.

Esta propuesta creo que se acerca más a la intencionalidad del constituyente, porque formalmente muestra un órgano constitucional independiente verdaderamente de autogobierno, ${ }^{86}$ pero no está exenta de debate, como todas las demás, y no es concluyente, porque el verdadero problema es sin embargo otro, y es que, si algo falla en la política española, hoy y ya hace un largo tiempo, es la decencia, la honradez, el respeto al contrario, la vocación de servicio a la ciudadanía, el sentido de Estado, el aprecio por la verdad, etc., en definitiva, fallan absolutamente todos los principios que conforman una buena moral pública, y que contribuirían a la aceptación sin fisuras del CGPJ.

Pero tiene remedio. Así, y sólo así, con una elección por los propios jueces y con ese nuevo gran acuerdo moral, estamos convencidos que la función principal

85 Como el Código de Ética Judicial, aprobado por el propio CGPJ el 16 de diciembre de 2016, a instancias de organismos internacionales en la lucha contra la corrupción (por ejemplo y entre otros, GRECO - Grupo de estados contra la corrupción- CONSEJO DE EUROPA-IV Evaluación Greco Informe 2013-CUARTA RONDA DE EVALUACIÓN, Prevención de la corrupción respecto de parlamentarios, jueces y fiscales, INFORME DE EVALUACIÓN ESPAÑA, Aprobado por GRECO en su 62. ${ }^{a}$ Reunión Plenaria (Estrasburgo, 2 a 6 de diciembre de 2013), en https://rm.coe.int/16806ca049, pp. 32 a 34).

86 Resumida por Cavero lataillade, I., en Alzaga Villaamil, Ó. (Dir.), Comentarios a la Constitución española de 1978, cit., p. 509. 
del Poder Judicial, garantizar la independencia de los jueces y magistrados españoles, podrá quedar salvaguardada. Sólo con un Consejo ideado y efectivamente constituido de esta manera, será real la independencia judicial en nuestro país. Es difícil pensar que entre cuarenta y cinco millones de españoles no se puedan encontrar veinte/veintiuna personas así cada cinco años.

Mientras estas acciones no se produzcan y sigamos con normas procedimentales para nombramientos establecidas en función de mayorías parlamentarias, la decisión última a favor de vocales y presidentes de primer nivel para nuestro Consejo General del Poder Judicial, dependerá de la voluntad de las personas, y si las personas no quieren, hay miles de formas legales de bordear, incluso de saltarse la ley, como nuestro reciente pasado ha demostrado.

Aun así, somos personas, capaces a veces de lo mejor. El acuerdo debe ser por ello posible.

$$
* * *
$$

TitLE: On the appointment of the President and Members of the Spanish General Council of the Judiciary. A reflection from common sense

AвSTRACT: Judicial independence is a key subjective principle of the democratic judiciary. Citizens expect, first and foremost, that whoever holds the State's power to resolve their conflict is unrelated to it, objective and impartial. Danger lurks when the system of appointment of judges, at least of the most important ones (the so-called high courts), depends directly on the political power and is not left to the judicial power itself, or depending only on the judiciary, the composition of the corresponding commission is clearly influenced by the political power. There is no perfect system for appointing high judges, nor is the Spanish system due to the political control of the General Council of the Judiciary. The causes, effects and possibilities of improvement are analysed in this paper, in order to better guarantee judicial independence.

Resumen: La independencia judicial es un principio subjetivo clave del poder judicial democrático. La ciudadanía espera, ante todo, que quien detenta el poder del estado para resolver su conflicto sea ajeno a él, objetivo e imparcial. Un peligro acecha cuando el sistema de nombramiento de los jueces, al menos de los más importantes (los llamados altos tribunales), depende directamente del poder político y no se deja al propio poder judicial, o dependiendo sólo del poder judicial, la composición de la correspondiente comisión está influida claramente por el poder político. No bay un sistema de nombramiento de los altos jueces perfecto, el español tampoco lo es por el control político del Consejo General del Poder Judicial. Se analizan aquí las causas, Los efectos y las posibilidades de mejora, para garantizar mejor la independencia judicial.

KEY wORDs: Spanish Constitution, Judiciary, General Council of the Judiciary, judicial councils, political control of Justice, appointment of judges, judicial independence.

Palabras Clave: Constitución española, Poder Judicial, Consejo General del Poder Judicial, consejos judiciales, control político de la Justicia, nombramiento de los jueces, independencia judicial.

FECHA DE RECEPCIÓN: 28.06.2019

FECHA DE ACEPTACIÓN: 11.09.2019 
